\title{
Synthesis and characterization of novel homo- and heterobimetallic palladium(0) and platinum(0) complexes of olefinic bismacrocyclic ligands.
}

\author{
Judit Masllorens, ${ }^{a}$ Anna Pla-Quintana, ${ }^{a}$ Teodor Parella ${ }^{b}$ and Anna Roglans ${ }^{\mathrm{a}, *}$ \\ ${ }^{a}$ Department of Chemistry, Universitat de Girona, 17071-Girona, Spain. ${ }^{b}$ NMR Service, \\ Universitat Autònoma de Barcelona, Cerdanyola, 08193-Barcelona, Spain \\ E-mail: anna.roglans@udg.edu
}

Dedicated to Professor Benito Alcaide (Madrid) on the occasion of his $60^{\text {th }}$ birthday

\begin{abstract}
Molecular structures featuring one or two triolefinic 15-membered azamacrocycles (1 and 6) as well as their homo- and heterobimetallic complexes of palladium(0) and platinum( 0$)(3,4$, and 7$)$ have been synthesized from biphenyl-4,4'-disulfonyl chloride. The strategy employed allows easy preparation of heterobimetallic complexes in a controlled manner. Pulsed-Field Gradients Spin-Echo (PFGSE) NMR techniques together with different mass spectrometry techniques can provide highly useful information about the structure of these polynuclear complexes.
\end{abstract}

Keywords: Olefinic macrocyclic complexes, bimetallic complexes, palladium, platinum, PFGSE

\section{Introduction}

The chemistry of macrocyclic compounds has progressed significantly in recent years to become one of the most important areas of research thanks, among other reasons, to the development in the synthesis and complexation of different types of macrocycles such as crown ethers, cryptans, spherands, porphyrines, and phthalocyanines. ${ }^{1}$ Many of these macrocyclic derivatives have been used, for example, as sensors, catalysts, imaging agents, molecular recognition scaffolds and to understand and mimic interactions found in nature. ${ }^{1}$

Functionalized polymacrocycles capable of coordinating metallic ions make it possible to synthesize polymetallic complexes with high levels of structural complexity. Despite this, the preparation of ligands with two or more different coordinating centers is not simple, and the coordination of two different metallic atoms to identical or similar ligands forming part of the same molecules is a difficult process. Mixtures of products, which at best can only be separated laboriously, are generally obtained. Given this, it is extremely interesting to develop a controlled synthesis of heteropolymetallic complexes. 
Synthesis of polymacrocyclic derivatives normally requires the use of spacers as a building block for the construction of the macromolecular structure. Several years ago the group of MorenoMañas published the synthesis and characterization of a novel type of nitrogen-containing 15membered triolefinic macrocyclic ligands ${ }^{2}(\mathrm{MC}=\mathbf{I}$ in Figure 1) as well as their palladium(0), platinum(0), and silver(I) complexes. ${ }^{3}$ Later we published the synthesis of new symmetric polymacrocyclic ligands and their homo- and heterometallic polynuclear complexes of palladium(0) and platinum(0) using 2,4,6-trichloro-1,3,5-triazine as the building block (Figure 1). ${ }^{4}$ The triazine derivative has the ability to replace, in a temperature-dependent stepwise manner, the three chlorine atoms by nucleophiles. ${ }^{5}$ The low solubility of the resulting palladium( $(0)$ complexes in common organic solvents makes them useful as recoverable catalysts, even though they have only shown moderate catalytic activity in certain cross-coupling reactions. ${ }^{4}$ As a further step forward in this study, we present here the synthesis of a new symmetric bismacrocyclic ligand $\mathbf{1}$ using biphenyl-4,4'-disulfonyl chloride 2 as a spacer $^{6}$ (Scheme 1) and the synthesis and characterization of $\mathrm{Pd}^{0}$-homobimetallic complex $\mathbf{3}$ (Scheme 1) and $\mathrm{Pd}^{0}-\mathrm{Pt}^{0}$-heterobimetallic complex 4 (Scheme 3).

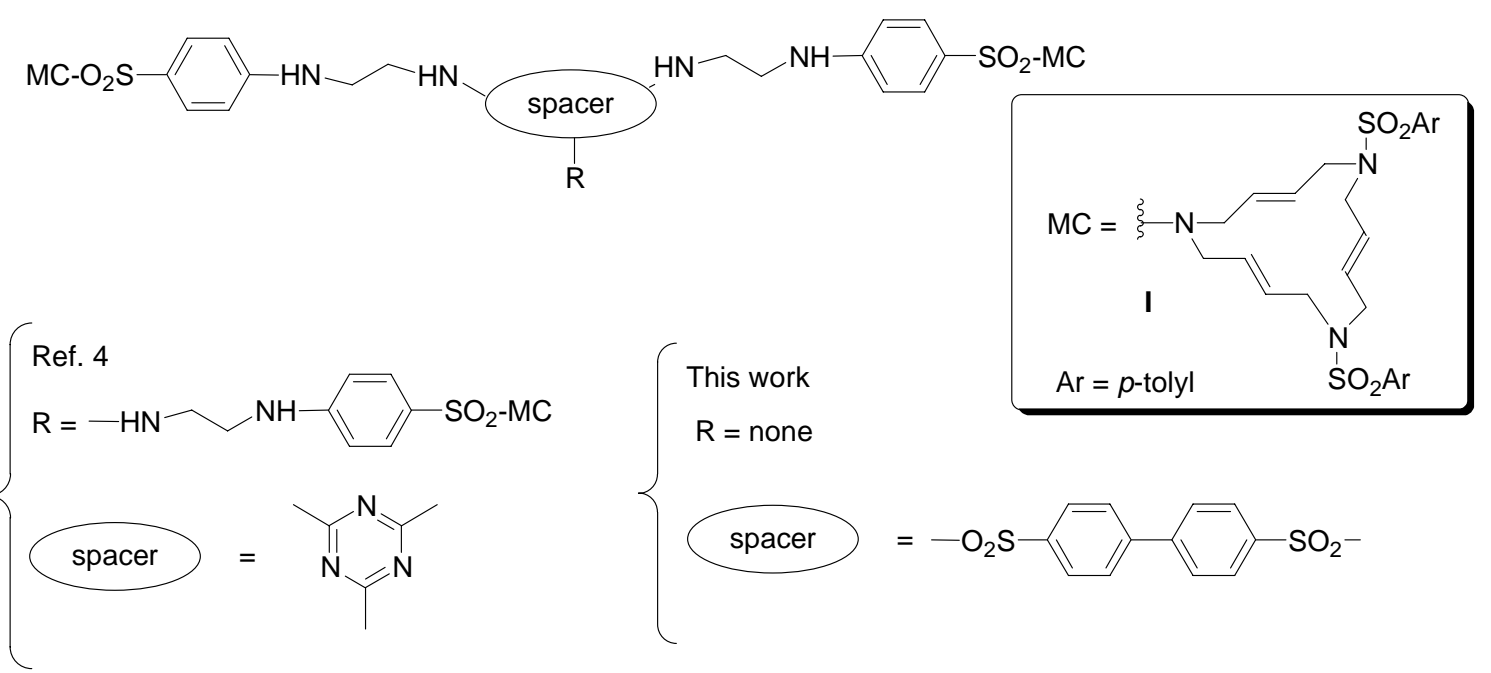

Figure 1. General structure of polymacrocyclic ligands.

\section{Results and Discussion}

In order to synthesize the bismacrocyclic ligand 1 (Scheme 1) we started with the 15 -membered triolefinic azamacrocycle $\mathbf{5}$, previously prepared by our group. ${ }^{4}$ Compound $\mathbf{5}$ has a nucleophilic terminal amino group capable of reacting with one of the two sulfonyl chloride groups in the central building block 2 . Thus, bismacrocyclic ligand $\mathbf{1}$ could be readily synthesized by the reaction of macrocycle 5 with 0.5 equivalents of disulfonyl chloride 2 . This was done in the presence of triethylamine in $\mathrm{CH}_{3} \mathrm{CN}$ at room temperature and a $68 \%$ yield of 1 was obtained. 
After obtaining the ligand, the next step was to prepare the metallic complexes. Bismacrocyclic ligand 1 was loaded with palladium(0) using bis(dibenzylideneacetone)palladium( 0 ) in refluxing THF to afford an $81 \%$ yield of bispalladium( 0 ) complex 3 .

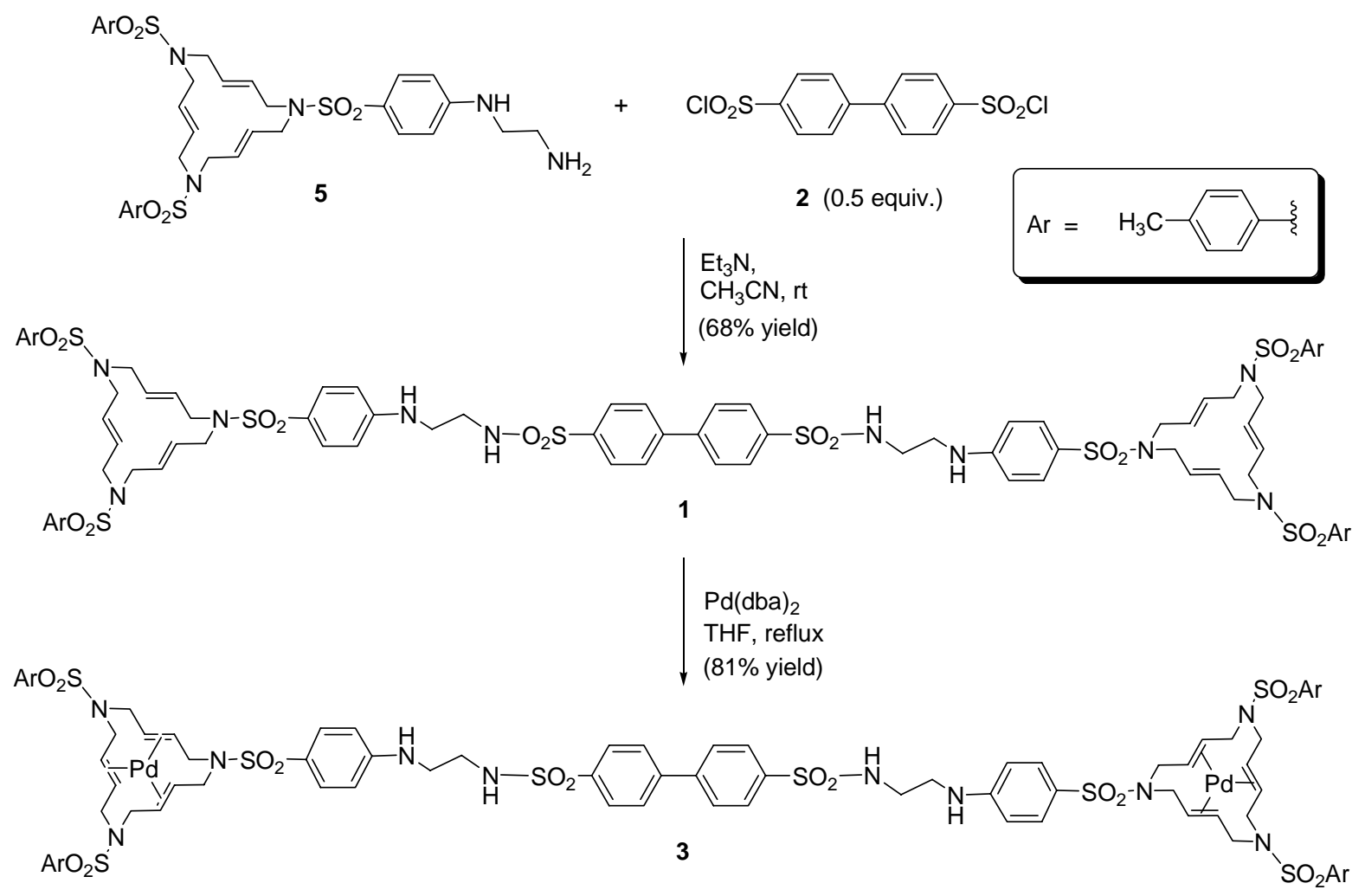

Scheme 1. Synthesis of 15-membered triolefinic bismacrocyclic ligand $\mathbf{1}$ and its bispalladium(0) complex 3.

However, given that the two coordinating ligands in the molecule are identical, the complexation of two different metals in the two macrocycles was expected to be a complicated task. A new strategy was therefore sought to achieve this. A stepwise reaction of the two macrocycles, each previously loaded with a different metal, was performed with the disulfonyl chloride linker 2. The strategy was first tested with the uncomplexed macrocycles as shown in Scheme 2. The key point was to achieve the monomacrocyclic derivative $\mathbf{6}$. The best conditions found were through the slow addition of one equivalent of macrocycle 5 to a solution of 1.4 equivalents of biphenyl-4,4'-disulfonyl chloride 2 in the presence of triethylamine in $\mathrm{CH}_{3} \mathrm{CN}$ at 0 ${ }^{\circ} \mathrm{C}$. A $50 \%$ yield of compound 6 was obtained together with a $37 \%$ yield of bismacrocyclic derivative 1. All attempts to improve the yield of $\mathbf{6}$ failed, but the two compounds, $\mathbf{6}$ and $\mathbf{1}$, could easily be separated by column chromatography. Afterwards, the synthesis of $\mathbf{1}$ was readily achieved, starting with monomacrocycle $\mathbf{6}$. The reaction of equimolar quantities of $\mathbf{5}$ and $\mathbf{6}$ under the same reaction conditions described above for the disubstitution afforded an $87 \%$ yield of compound 1 (Scheme 2). 


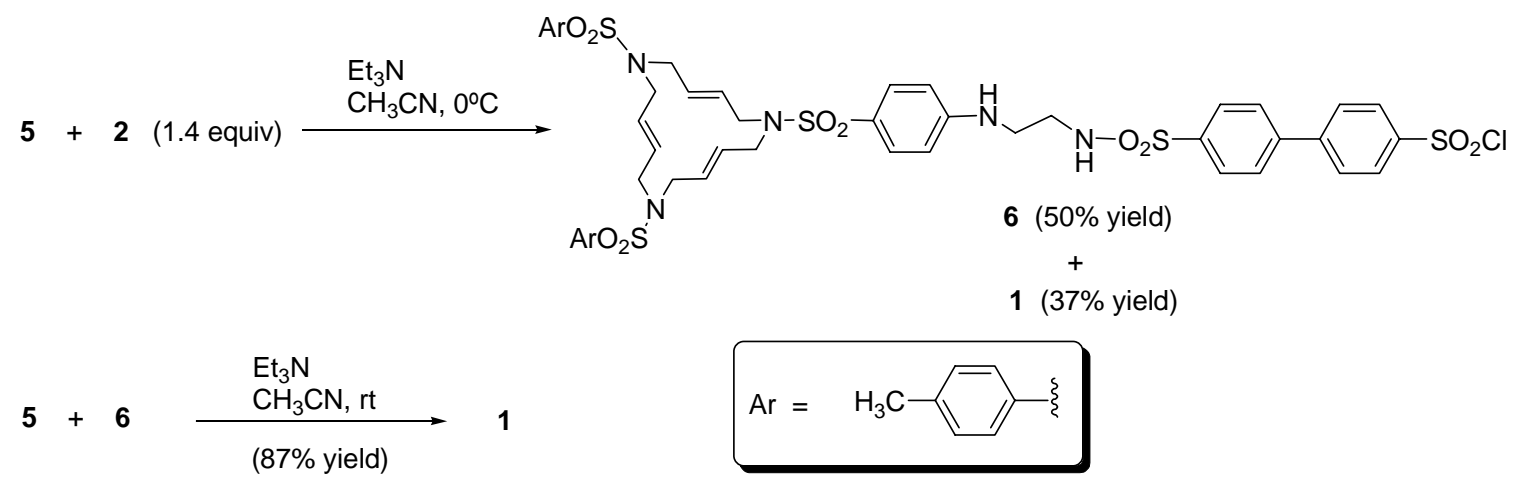

Scheme 2. Stepwise synthesis of 15-membered triolefinic bismacrocyclic ligand $\mathbf{1}$.

Once the effectiveness of the strategy was proven with the uncomplexed macrocycles, the synthesis of the heterobimetallic complex 4 was tackled (Scheme 3). Monomacrocyclic ligand 6 was loaded with palladium( $(0)$ using bis(dibenzylideneacetone)palladium $(0)$ in refluxing THF to afford a $74 \%$ yield of palladium(0) complex 7 . A $47 \%$ yield of heterobimetallic palladium(0)platinum(0) complex 4 was then obtained by the reaction of two units, $\mathbf{7}$ and $\mathbf{8}$, each already possessing a different metal atom. Platinum(0) complex of the 15-membered azamacrocycle 8 was previously prepared by us. ${ }^{4}$ The reaction took place in the presence of triethylamine in THF at room temperature (Scheme 3).

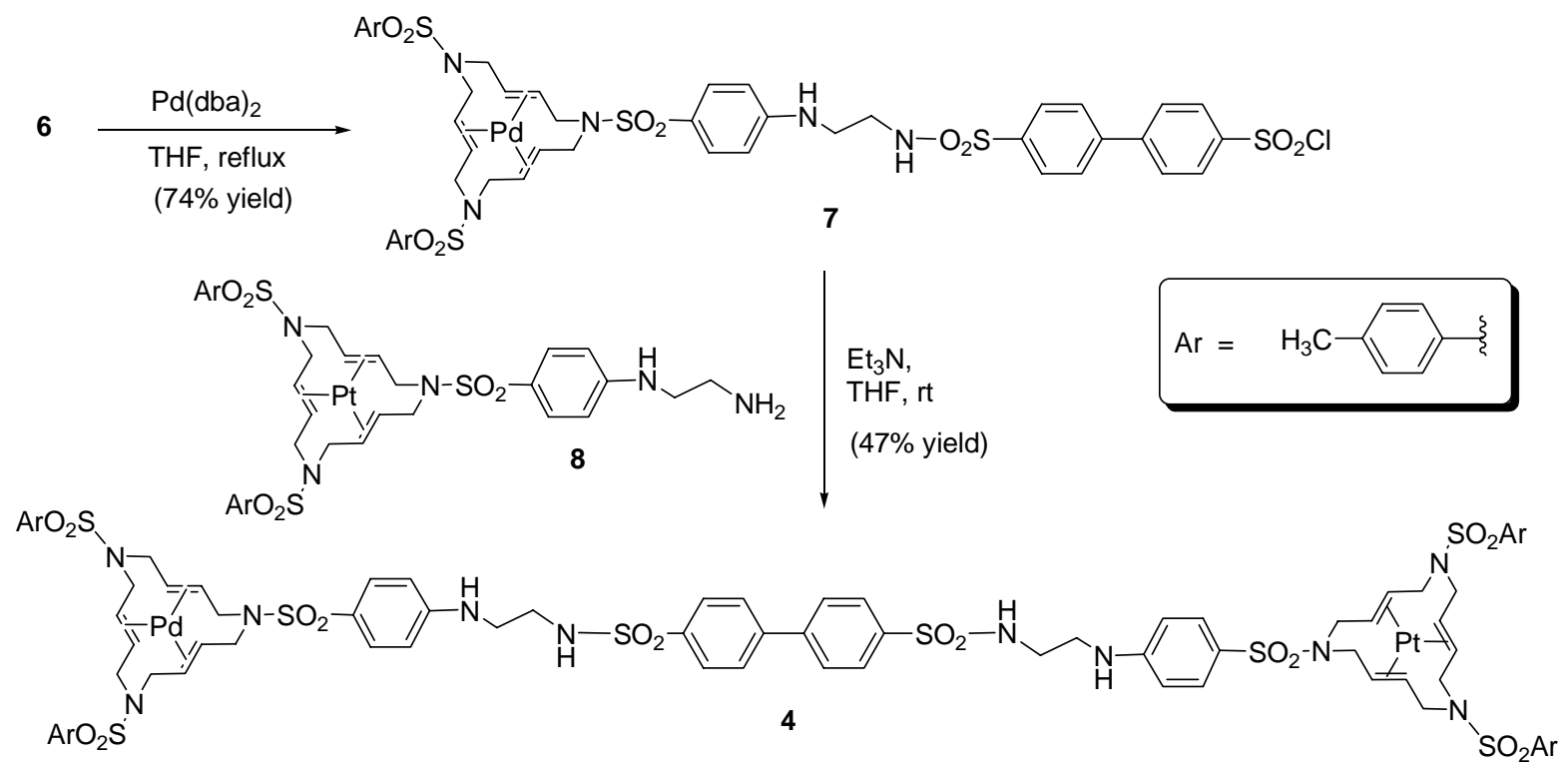

Scheme 3. Synthesis of $\mathrm{Pd}^{0}-\mathrm{Pt}^{0}$ heterobimetallic complex 4 .

Macromolecular chemistry has a high level of structural complexity which often makes it difficult to determine the structure of the synthesized compounds with the usual spectroscopic techniques. This problem is more severe in the case of structures built out of identical monomeric units as it is fairly difficult to determine the number of monomer units they have 
using common NMR techniques. In our case, biphenyl-4,4'-disulfonyl chloride 2 is a spacer containing aromatic protons and, therefore, it is possible to determine through the ${ }^{1} \mathrm{H}-\mathrm{NMR}$ spectra whether or not the introduced macrocycles are connected to the spacer. In this way, the symmetry of the aromatic signals tells us whether the molecule has one or two macrocycles. Symmetrical signals for the two phenyl units of the spacer indicate the formation of bismacrocycle 1. Similarly, in the case of synthesized complexes 3 and 4, NMR enables us to discover whether or not we have a mono- or a bis-macrocyclic derivative. However, the full characterization of metallic complexes 7, 3, and $\mathbf{4}$ is more difficult. Thus, the insertion of a metal $\mathrm{Pd}$ or $\mathrm{Pt}$ atom into the cavity of the macrocycle leads to significant changes in the ${ }^{1} \mathrm{H}$ and ${ }^{13} \mathrm{C}$ NMR spectra, as previously reported. ${ }^{7}$ The coordination of the metal center to one of the two olefinic faces of every double bond in the macrocycle gives rise to a number of highly rigid stereoisomers which varies depending on the equality or inequality of the substituents of the nitrogen. In the case of palladium complex 7, two different enantiomer pairs are formed in a proportion of $2: 1$ as a function of the different chair/twist conformations of the multiple sixmembered Pd-containing rings. On the other hand, for each individual bimetallic complex $\mathbf{3}$ or $\mathbf{4}$, a major number of diastereosisomers are finally present with several degrees of molecular symmetry. In practice, NMR spectra of all these species show broad, unresolved signals resulting from the great number of overlapping NMR resonances as they all usually appear within a very narrow chemical shift range for each proton or carbon atom, making their precise assignment difficult. This complexity is further increased when more than one complex is present in the structure as is the case for homobimetallic complex 3 and heterobimetallic complex $\mathbf{4}$. In summary, conventional $1 \mathrm{D}$ and $2 \mathrm{D}{ }^{1} \mathrm{H}$ and ${ }^{13} \mathrm{C}$ NMR spectral analysis of all these polynuclear complexes became highly complicated and, as a result, relatively uninformative from the structural point of view. Therefore, complementary techniques were sought to complete the structural characterization of these polynuclear complexes. Self-diffusion NMR experiments using Pulsed-Field Gradients Spin-Echo (PFGSE) techniques can provide useful information on these polynuclear complexes in solution conditions. ${ }^{8}$ Such experiments make it possible to determine the overall molecular size of a series of molecules in solution, even when several compounds are present in the reaction mixture. In general, PFGSE experiments permit the determination of diffusion coefficients through the study of the translation diffusion properties of the molecules so providing information regarding the molecular sizes and shapes. The impurities or compound mixtures are not problematic as identifiable isolated peaks can be individually evaluated. 
Table 1. Diffusion coefficients determined by PGSE NMR in $\mathrm{CDCl}_{3}$ at $298 \mathrm{~K}$

\begin{tabular}{lll}
\hline Compound & Molecular Weight & $\begin{array}{l}\text { Diffusion Coefficient } \\
\mathrm{D}^{*} 10^{-10}\left(\mathrm{~m}^{2} / \mathrm{s}\right)\end{array}$ \\
\hline 5 & 713.92 & 10.00 \\
6 & 1028.73 & 8.71 \\
7 & 1135.15 & 8.31 \\
1 & 1706.07 & 6.31 \\
3 & 1918.98 & 5.57 \\
4 & 2007.67 & 5.49 \\
$9^{\mathrm{a}}$ & 673.83 & 11.7 \\
$10^{\mathrm{a}}$ & 861.97 & 10 \\
$11^{\mathrm{a}}$ & 868.92 & 11.2 \\
$12^{\mathrm{a}}$ & 968.37 & 8.13 \\
$13^{\mathrm{a}}$ & 1539.38 & 7.24 \\
$14^{\mathrm{a}}$ & 1752.18 & 6.31 \\
$15^{\mathrm{a}}$ & 1840.88 & 6.31 \\
$16^{\mathrm{a}}$ & 2216.80 & 5.37 \\
$17^{\mathrm{a}}$ & 2536.06 & 4.47 \\
\hline
\end{tabular}

${ }^{\mathrm{a}}$ Compounds synthesized in reference 4 . 


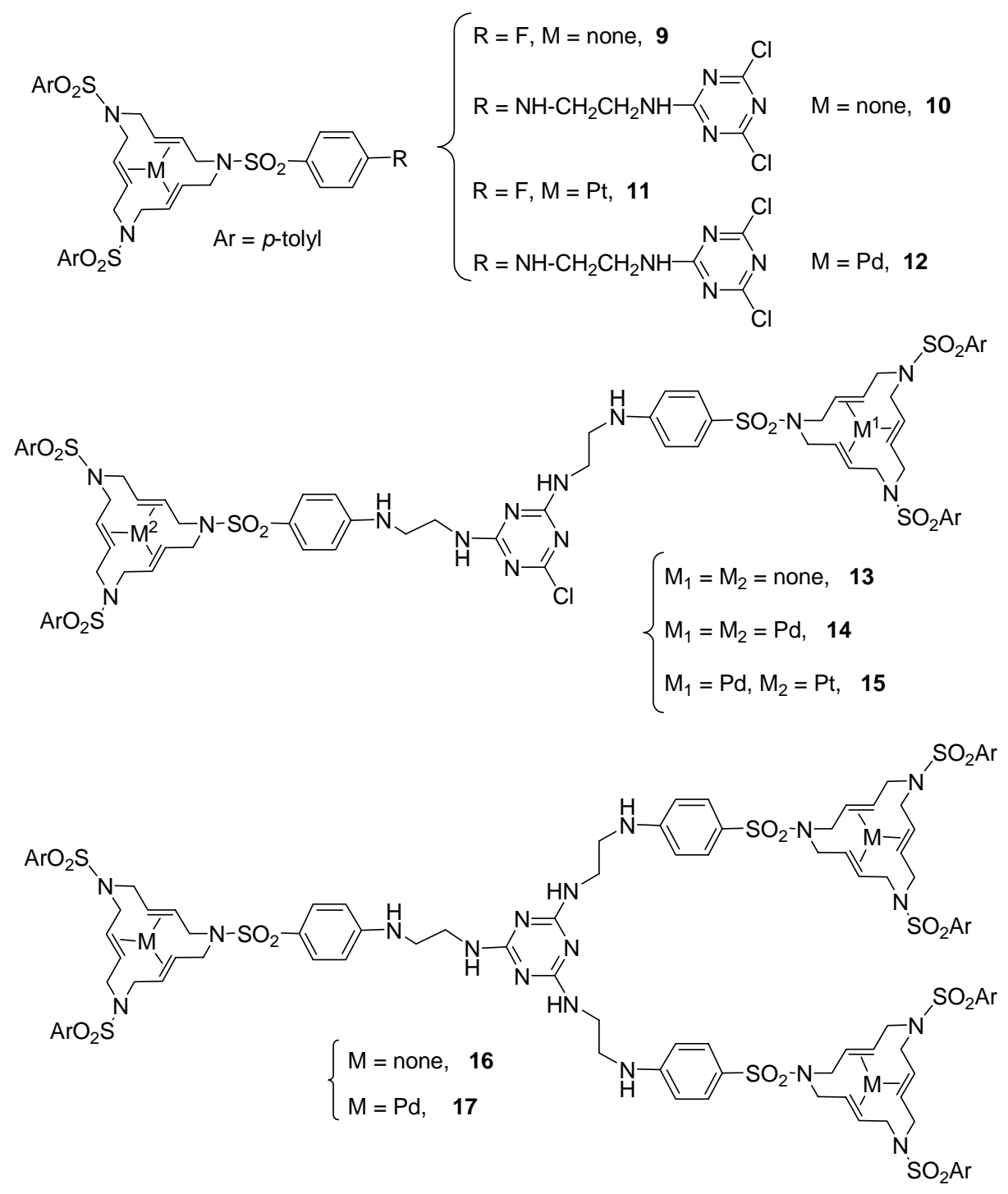

Figure 2. Structures of macrocyclic ligands and their homo- and heterometallic complexes with a triazine spacer. ${ }^{4}$

In our case, in which the monomeric unit common to all of the compounds is a macrocyclic unit of type I (Figure 1), this technique makes it possible to discover whether there is a monomacrocycle or bismacrocycle and to distinguish between free and complexed ligands. In this way, more detailed confirmation of the structure and characterization of the polymacrocyclic derivatives is obtained as a complement to mass spectrometry and conventional NMR studies. In Table 1 and Figure 3 data obtained through PFGSE NMR of the diffusion coefficients of the different synthesized ligands and complexes are set out. In addition, and in order to show the excellent experimental correlation with their molecular weight, diffusion data for the uncomplexed and complexed monomeric species and related triazine derivatives previously published by us $^{4}$ are shown in Figure 2. It is generally assumed that the diffusion coefficient D 
varies reciprocally as the mass $(\mathrm{M})$ to the power of two-thirds. Thus, in a theoretically spherical and isotropic molecular average, $\mathrm{D}$ varies as 1/A (A is the molecular cross section surface area) and, therefore, a strong correlation must be given between $\mathrm{D}$ and $1 / \mathrm{MW}^{2 / 3}$ for similar shaped molecules, as shown in Figure 3.

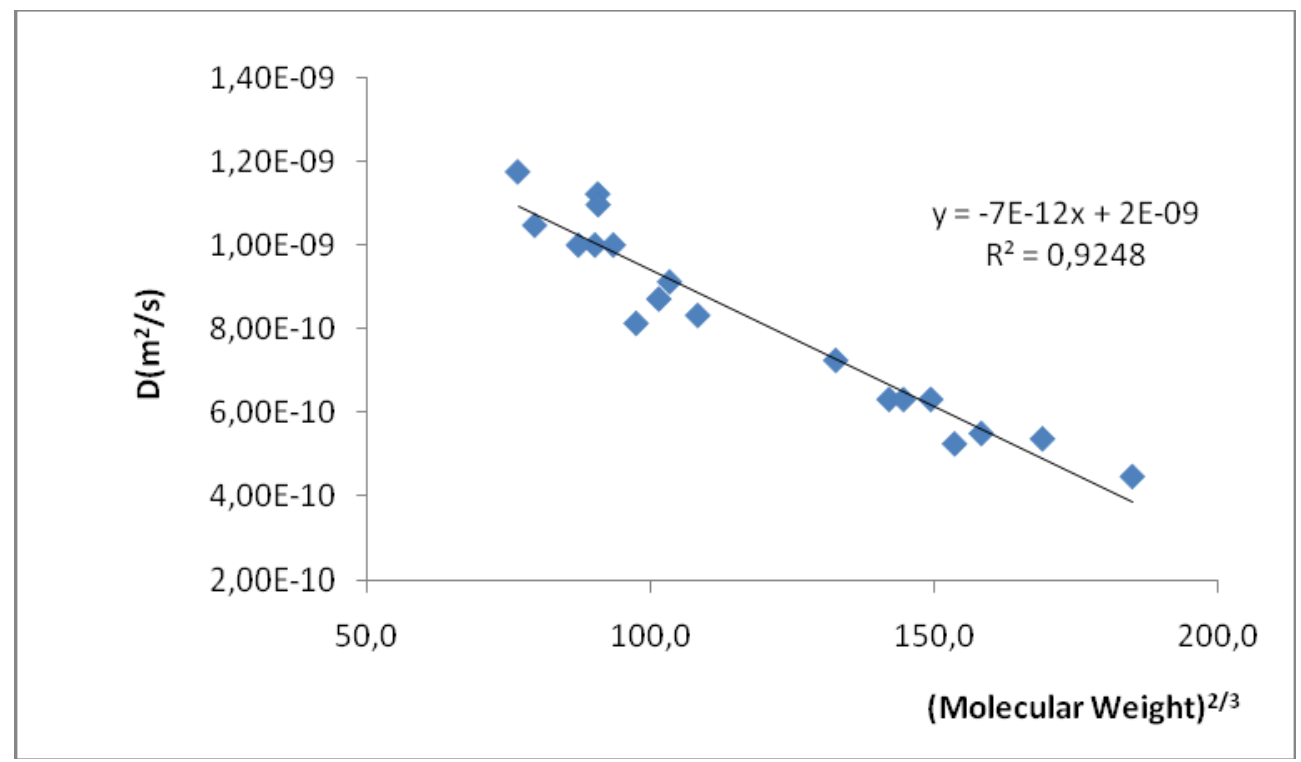

Figure 3. Experimental correlation between diffusion NMR data and molecular weights for compounds 5, 6, 7, 1, 3, and 4 prepared in this study and uncomplexed (9 and 10) and complexed (11 and 12) monomeric species and related triazine derivative compounds (13-17) (see Table 1) reported in ref. 4.

As a general trend, as the molecular size of the compounds and hence the number of macrocyclic units increase, the diffusion coefficient is reduced. Therefore, the monomacrocyclic compounds diffuse faster than the bismacrocycles. In the case of the metallic derivatives, the diffusion coefficient shows the effect of the metal atom although the overall size does not change. However, there is a little influence due to the nature of the metallic atom introduced. This may be explained by the fact that the contact surface, and consequently the volume of the ligand and the complex, does not vary significantly and so the movement is quite similar despite the increase in the molecular weight.

This linear relationship should prove to be of great use in determining the structure of polymacrocyclic compounds that are related to those studied in this paper. In practical terms, once the compound has been synthesized, the diffusion coefficient can be determined through PFGSE NMR and an approximate value of its molecular weight and, therefore, an estimation of the number of macrocyclic units it contains, is obtained through the previously mentioned lineal relationship. All these diffusion data can be correlated with other related macrocyle derivatives, such as those having a triazine moiety as a spacer (see Table 1 and Figure 2). ${ }^{4}$ 
Complementary structural information for these compounds was obtained by mass spectrometric techniques. These techniques proved to be highly useful, particularly those involving ionization in soft conditions, as they avoid fragmentation and enable us to observe the molecular weight of most compounds, and, more interestingly, those containing metallic atoms (entries 3, 4, and 5, Table 2).

Table 2. Peaks observed in the mass spectra of the synthesized ligands and complexes

\begin{tabular}{|c|c|c|c|c|}
\hline Entry & Compound & $\begin{array}{c}\text { Calculated } \\
{[\mathrm{M}]^{\mathrm{a}}}\end{array}$ & $\begin{array}{c}\text { ESI-MS } \\
(m / z)\end{array}$ & $\begin{array}{l}\text { LSI-MS } \\
\qquad(\mathrm{m} / \mathrm{z})\end{array}$ \\
\hline 1 & 6 & 1027 & $\begin{array}{c}1028 \\
{[\mathrm{M}+\mathrm{H}]^{+}}\end{array}$ & Not performed \\
\hline 2 & 1 & 1705 & $\begin{array}{c}853 \\
{[(\mathrm{M}+2 \mathrm{H}) / 2]^{2+}}\end{array}$ & $\begin{array}{c}1706 \\
{[\mathrm{M}+\mathrm{H}]^{+}}\end{array}$ \\
\hline 3 & 7 & 1135 & $\begin{array}{c}1136 \\
{[\mathrm{M}+\mathrm{H}]^{+}}\end{array}$ & Not performed \\
\hline 4 & 3 & 1918 & $\begin{array}{c}960 \\
{[(\mathrm{M}+2 \mathrm{H}) / 2]^{2+}}\end{array}$ & $\begin{array}{c}1919 \\
{[\mathrm{M}+\mathrm{H}]^{+}}\end{array}$ \\
\hline 5 & 4 & 2007 & & $\begin{array}{c}2008 \\
{[\mathrm{M}+\mathrm{H}]^{+}}\end{array}$ \\
\hline
\end{tabular}

${ }^{\mathrm{a}}$ Calculated mass of the highest peak of the isotopic distribution

For monomacrocyclic compounds 6 and 7, molecular peak $[\mathrm{M}+\mathrm{H}]^{+}$was observed using ESI mass spectrometry. For compounds $\mathbf{1}$ and 3, peaks corresponding to the dicharged species $[(\mathrm{M}+2 \mathrm{H}) / 2]^{2+}$ were observed, but the molecular mass could not be detected since they were too high for the range of masses of our detector. An additional analysis of compounds 1, 3, and 4 was therefore undertaken with LSI mass spectrometry. In all three cases the molecular peak $[\mathrm{M}+\mathrm{H}]^{+}$was observed.

\section{Conclusions}

The synthesis of macromolecular structures containing two triolefinic azamacrocycles linked through a biphenyl-4,4'-disulfonyl moiety has been achieved. A homobimetallic palladium(0) complex of the bismacrocyclic structure has been readily obtained by ligand exchange with a palladium( $(0)$ source. Also a heterobimetallic palladium $(0)$ and platinum(0) complex has been synthesized through a stepwise synthesis in which the two macrocycles were previously loaded with the two different metals. PFGSE NMR experiments have proved useful for the determination of the number of monomeric units contained in the polymacrocyclic ligands and complexes synthesized, as well as in related polymacrocyclic ligands built up around a triazine 
core. Soft ionization mass techniques complemented NMR data by allowing the determination of the molecular mass of both ligands and bimetallic complexes.

\section{Experimental Section}

General Procedures. Compounds 5 and $\mathbf{8}$ were prepared as previously reported by us. ${ }^{4}$ ESI (electrospray ionization) mass spectra were acquired using a Navigator quadrupole mass spectrometer (Finnigan AQA ThermoQuest) equipped with an electrospray ion source. The instrument was operated in the positive-ion mode $(\mathrm{ESI}+)$ at a probe tip voltage of $3 \mathrm{kV}$. LSI (liquid secondary ion) mass spectra were recorded on a VG-Autospec EBE mass spectrometer. 3Nitrobenzyl alcohol (3-NBA) was used as LSI MS matrix, and the standard $\mathrm{Cs}^{+}$gun was operated at $30 \mathrm{kV}$. Elemental analyses were performed on a CHNS-O EA-1108 analyzer (Fisons) at the Research Technical Services of the University of Girona.

\section{NMR Spectroscopy}

${ }^{1} \mathrm{H}$ NMR, ${ }^{13} \mathrm{C}\left\{{ }^{1} \mathrm{H}\right\}$ NMR, HSQC, COSY and NOESY spectra were recorded on a Bruker AVANCE $250 \mathrm{MHz}$ NMR spectrometer and Bruker DPX-200 MHz NMR spectrometer in $\mathrm{CDCl}_{3}$ or $\mathrm{CD}_{3} \mathrm{CN}$ solutions at 298K. NMR diffusion experiments were carried out at $298 \mathrm{~K}$ on a $500 \mathrm{MHz}$ AVANCE spectrometer equipped with a $5 \mathrm{~mm}$ TCI cryoprobe. Self-diffusion experiments were performed using the compensated BPLED pulse sequence ${ }^{9}$ using a diffusion time of $150 \mathrm{~ms}$ and a LED delay of $5 \mathrm{~ms}$. For each experiment, sine-shaped pulsed-field gradients with a duration of $1.5 \mathrm{~ms}$ followed by a recovery delay of $100 \mu \mathrm{s}$ were incremented from $2 \%$ to $95 \%$ of the maximum strength in 16 equally spaced steps. Diffusion coefficients were obtained by measuring the slope in the following linear relationship: $\ln \left(\mathrm{A}_{\mathrm{g}} / \mathrm{A}_{\mathrm{o}}\right)=-\gamma^{2} \mathrm{~g}^{2} \delta^{2}$ $(4 \Delta-\delta) D$; where $A_{g}$ and $A_{o}$ are the signal intensities in the presence and absence of pulsed field gradient (PFG), respectively, $\gamma$ is the gyromagnetic ratio $\left(\mathrm{rad} \mathrm{s} \mathrm{g}^{-1}\right), \mathrm{g}$ is the strength of the diffusion gradients (gauss $\left.\mathrm{cm}^{-1}\right), D$ is the diffusion coefficient of the observed spins $\left(\mathrm{m}^{2} \mathrm{~s}^{-1}\right), \delta$ is the length of the diffusion gradient (s) and $\Delta$ is the time separation between the leading edges of the two diffusion pulsed gradients (s). All chemical shifts values $(\delta)$ are given in ppm.

All the reported D values are derived from lines that have correlation coefficients of $>0.99$. The error in D values based on our experience with diffusion measurements is $0.06 * 10^{-10} \mathrm{~m}^{2} \mathrm{~s}^{-1}$.

\section{Monomacrocycle biphenylsulfonyl derivative (Ar $=p$-tolyl) (6) and bismacrocycle biphenyldisulfonamide derivative (Ar = p-tolyl) (1). A solution of biphenyl-4,4'-disulfonyl chloride $2(0.038 \mathrm{~g}, 0.10 \mathrm{mmol})$ and triethylamine $(0.05 \mathrm{~mL}, 0.35 \mathrm{mmol})$ in anhydrous $\mathrm{CH}_{3} \mathrm{CN}$ $(5 \mathrm{~mL})$ under argon atmosphere was cooled at $0-5^{\circ} \mathrm{C}$ (ice- $\mathrm{H}_{2} \mathrm{O}$ bath) and stirred for a few minutes. Then a degassed solution of $5(0.05 \mathrm{~g}, 0.07 \mathrm{mmol})$ in anhydrous $\mathrm{CH}_{3} \mathrm{CN}(5 \mathrm{~mL})$ was added slowly. The mixture was stirred at $0^{\circ} \mathrm{C}$ for $1 \mathrm{~h}$ (TLC monitoring). The solvent was removed under reduced pressure, and the residue was purified by column chromatography on silica gel ( $n$ -}


hexane-EtOAc, polarity from 4:6 to 0:10). First compound eluted was $6(0.036 \mathrm{~g}, 50 \%)$, colorless solid. M. p. 129-131 ${ }^{\circ} \mathrm{C}$ (n-hexane). IR (KBr): v 3385, 3278, 2923, 1598, 1328, $1152 \mathrm{~cm}^{-1} .{ }^{1} \mathrm{H}$ NMR $\left(200 \mathrm{MHz}, \mathrm{CDCl}_{3}, 25^{\circ} \mathrm{C}\right.$, TMS): $\delta 2.43$ (s, 6H), 3.27 (ap t, 2H), 3.40 (ap t, 2H), 3.62 (br abs, 8H), 3.71 (br abs, 4H), 5.25 (br abs, 1H), 5.51 (br abs, 6H), 6.60 (d, J=8.6 $\mathrm{Hz}, 2 \mathrm{H}), 7.31(\mathrm{~d}, J=8.2 \mathrm{~Hz}, 4 \mathrm{H}), 7.54(\mathrm{~d}, J=8.4 \mathrm{~Hz}, 2 \mathrm{H}), 7.65(\mathrm{~d}, J=8.0 \mathrm{~Hz}, 4 \mathrm{H}), 7.71(\mathrm{~d}, J=$ $8.4 \mathrm{~Hz}, 2 \mathrm{H}), 7.80(\mathrm{~d}, J=8.4 \mathrm{~Hz}, 2 \mathrm{H}), 7.96(\mathrm{~d}, J=8.2 \mathrm{~Hz}, 2 \mathrm{H}), 8.14(\mathrm{~d}, J=8.4 \mathrm{~Hz}, 2 \mathrm{H}) .{ }^{13} \mathrm{C}$ NMR (50 MHz, $\left.\mathrm{CDCl}_{3}, 25^{\circ} \mathrm{C}, \mathrm{TMS}\right): \delta 22.2,42.6,43.7,51.2,51.4,112.7,126.9,127.8,128.5$, 128.6, 128.9, 129.3, 129.9, 130.0, 130.1, 130.6, 136.5, 141.0, 143.5, 144.4, 144.6, 146.8, 151.9. ESI-MS (m/z): $1028[\mathrm{M}+\mathrm{H}]^{+}$. Anal. Calcd for $\mathrm{C}_{46} \mathrm{H}_{50} \mathrm{ClN}_{5} \mathrm{O}_{10} \mathrm{~S}_{5}(1028.7): \mathrm{C}, 53.71 ; \mathrm{H}, 4.90 ; \mathrm{N}$, 6.81. Found: C, 53.69 and 53.78; H, 5.17 and 5.13; N, 6.54 and 6.54.

Second compound eluted was 1 (0.022 g, 37\%), colorless solid. Mp: 130-132 ${ }^{\circ} \mathrm{C}(n-$ hexane $/ \mathrm{CH}_{2} \mathrm{Cl}_{2}$ ). IR (KBr): $v$ 3381, 3286, 2925, 1598, 1326, $1150 \mathrm{~cm}^{-1}$. ${ }^{1} \mathrm{H}$ NMR (200 MHz, $\left.\mathrm{CDCl}_{3}, 25{ }^{\circ} \mathrm{C}, \mathrm{TMS}\right): \delta 2.42$ (s, 12H), 3.29 (br abs, 8H), 3.63 (br abs, 24H), 4.74 (br abs, 2H), 5.53 (br abs, 12H), 6.49 (d, $J=8.0 \mathrm{~Hz}, 4 \mathrm{H}), 7.31$ (d, $J=8.2 \mathrm{~Hz}, 8 \mathrm{H}), 7.44$ (d, $J=8.4 \mathrm{~Hz}, 4 \mathrm{H})$, $7.61(\mathrm{~m}, 12 \mathrm{H}), 7.92(\mathrm{~d}, J=8.0 \mathrm{~Hz}, 4 \mathrm{H}) .{ }^{13} \mathrm{C} \mathrm{NMR}\left(50 \mathrm{MHz}, \mathrm{CDCl}_{3}, 25{ }^{\circ} \mathrm{C}, \mathrm{TMS}\right): \delta 22.2,42.6$, 43.4, 51.4, 112.6, 126.0, 127.8, 128.4, 128.6, 129.8, 130.0, 130.2, 130.6, 136.5, 140.3, 143.9, 144.4, 152.0. ESI-MS (m/z): $853[(\mathrm{M}+2 \mathrm{H}) / 2]^{2+}$. LSI-MS $(\mathrm{m} / \mathrm{z}): 1706[\mathrm{M}+\mathrm{H}]^{+}$. Anal. Calcd for $\mathrm{C}_{80} \mathrm{H}_{92} \mathrm{~N}_{10} \mathrm{O}_{16} \mathrm{~S}_{8} .1 / 2 \mathrm{CH}_{2} \mathrm{Cl}_{2}$ (1748.6): C, 55.29; H, 5.36; N, 8.01. Found: $\mathrm{C}, 55.14$ and 55.26; H, 5.50 and $5.47 ; \mathrm{N}, 7.77$ and 7.75 .

Pd $^{\mathbf{0}}$ Complex of monomacrocycle biphenylsulfonyl derivative (7). A magnetically stirred solution of monomacrocicle biphenylsulfonyl derivative $6(0.037 \mathrm{~g}, 0.036 \mathrm{mmol})$ and bis(dibenzylideneacetone)palladium(0) $(0.027 \mathrm{~g}, 0.047 \mathrm{mmol})$ in THF (4 mL) was refluxed for $2.5 \mathrm{~h}$ (TLC monitoring). The solvent was removed under reduced pressure, and the residue was purified by column chromatography on silica gel ( $n$-hexane-EtOAc, polarity from 5:5 to 4:6) to afford 7 as a colorless solid (0.0305 g, 74\%). M.p. 184-186 ${ }^{\circ} \mathrm{C}$ (dec). IR (ATR): v 2923, 1598, 1327, $1153 \mathrm{~cm}^{-1} .{ }^{1} \mathrm{H}$ NMR (200 MHz, $\left.\mathrm{CDCl}_{3}, 25^{\circ} \mathrm{C}, \mathrm{TMS}\right): \delta 1.50-1.90(\mathrm{~m}, 4 \mathrm{H}), 2.38(\mathrm{~s}, 6 \mathrm{H})$, $2.81(\mathrm{t}, J=12.2 \mathrm{~Hz}, 2 \mathrm{H}), 3.06(\mathrm{t}, J=12.9 \mathrm{~Hz}, 2 \mathrm{H}), 3.10 .-3.35(\mathrm{~m}, 4 \mathrm{H}), 3.55-3.80(\mathrm{~m}, 2 \mathrm{H}), 3.95$ $(\mathrm{t}, J=11.1 \mathrm{~Hz}, 2 \mathrm{H}), 4.45-4.85(\mathrm{~m}, 6 \mathrm{H}), 5.40(\mathrm{br} \mathrm{s}, 1 \mathrm{H}), 6.52(\mathrm{~d}, J=8.4 \mathrm{~Hz}, 2 \mathrm{H}), 7.28(\mathrm{~d}, J=8.0$ $\mathrm{Hz}, 4 \mathrm{H}), 7.46(\mathrm{~d}, J=8.4 \mathrm{~Hz}, 2 \mathrm{H}), 7.63(\mathrm{~d}, J=8.0 \mathrm{~Hz}, 4 \mathrm{H}), 7.72(\mathrm{~d}, J=7.7 \mathrm{~Hz}, 2 \mathrm{H}), 7.81$ (d, $J=$ $8.4 \mathrm{~Hz}, 2 \mathrm{H}), 7.96(\mathrm{~d}, J=7.7 \mathrm{~Hz}, 2 \mathrm{H}), 8.14(\mathrm{~d}, J=8.4 \mathrm{~Hz}, 2 \mathrm{H}) .{ }^{13} \mathrm{C} \mathrm{NMR}\left(50 \mathrm{MHz}, \mathrm{CDCl}_{3}\right.$, $\left.25{ }^{\circ} \mathrm{C}, \mathrm{TMS}\right): \delta 22.2,42.7,43.7,45.8,48.9,50.2,78.9,79.0,79.1,79.2,79.3,79.5,83.3,83.4$, $83.8,112.7,125.7,127.7,127.8,128.5,129.0,129.3,129.9,130.5,135.9,136.0,136.7,140.8$, 143.6, 144.1, 144.3, 144.6, 146.7, 151.7. ESI-MS (m/z): $1028[\mathrm{M}-\mathrm{Pd}+\mathrm{H}]^{+}, 1136[\mathrm{M}+\mathrm{H}]^{+}$. Anal. Calcd for $\mathrm{C}_{46} \mathrm{H}_{50} \mathrm{ClN}_{5} \mathrm{O}_{10} \mathrm{~S}_{5} \mathrm{Pd}$ (1135.1): C, 48.67; H, 4.44; N, 6.17. Found: $\mathrm{C}, 48.85$ and 48.25; H, 4.90 and 4.99; N, 5.60 and 6.02.

Homobimetallic $\mathbf{P d}^{\mathbf{0}}$ Complex (3). A magnetically stirred solution of bismacrocycle biphenyldisulfonamide derivative 1 (0.052 g., $0.030 \quad \mathrm{mmol})$ and bis(dibenzylideneacetone)palladium(0) $(0.046 \mathrm{~g}, 0.079 \mathrm{mmol})$ in THF $(8 \mathrm{~mL})$ was refluxed for $3 \mathrm{~h}$ (TLC monitoring). The solvent was removed under reduced pressure, and the residue was purified by column chromatography on silica gel (from $n$-hexane-EtOAc (6:4) to EtOAc- $\mathrm{CH}_{2} \mathrm{Cl}_{2}$ 
(9:1)) to afford 3 as a colorless solid $\left(0.0475\right.$ g, 81\%). M.p. $195-197^{\circ} \mathrm{C}(\mathrm{dec}) . \mathrm{IR}(\mathrm{ATR}): v 3385$, 3278, 2923, 1598, 1328, $1152 \mathrm{~cm}^{-1} .{ }^{1} \mathrm{H}$ NMR (200 MHz, $\left.\mathrm{CDCl}_{3}, 25{ }^{\circ} \mathrm{C}, \mathrm{TMS}\right): \delta 1.40-1.85$ (m, 4H), 2.36 (br s, 12H), 2.55-2.90 (m, 4H), 2.90-3.15 (m, 4H), 3.24 (br abs, 4H), 3.68 (br abs, 4H), 3.75-4.05 (m, 4H), 4.37-4.85 (m, 12H), 6.38-6.52 (m, 4H), $7.26(\mathrm{~d}, J=8.0 \mathrm{~Hz}, 8 \mathrm{H}), 7.30-7.50$ $(\mathrm{m}, 4 \mathrm{H}), 7.50-7.75(\mathrm{~m}, 4 \mathrm{H}), 7.62(\mathrm{~d}, J=8.0 \mathrm{~Hz}, 8 \mathrm{H}), 7.91(\mathrm{~d}, J=7.8 \mathrm{~Hz}, 4 \mathrm{H}) .{ }^{13} \mathrm{C}$ NMR $(50$ $\mathrm{MHz}, \mathrm{CDCl}_{3}, 25^{\circ} \mathrm{C}$, TMS): $\delta$ 22.8, 44.1, 45.2, 47.5, 50.5, 51.6, 80.1, 80.2, 80.5, 80.6, 80.7, 81.0, $84.9,85.6,113.5,126.8,129.4,129.5,129.9,130.1,131.8,138.4,138.5,139.2,143.5,145.2$, 145.3, 145.4, 154.1. ESI-MS (m/z): $960[(\mathrm{M}+2 \mathrm{H}) / 2]^{+}$. LSI-MS $(\mathrm{m} / \mathrm{z}) 1919[\mathrm{M}+\mathrm{H}]^{+}$. Anal. Calcd for $\mathrm{C}_{80} \mathrm{H}_{92} \mathrm{~N}_{10} \mathrm{O}_{16} \mathrm{~S}_{8} \mathrm{Pd}_{2} \cdot \mathrm{CH}_{2} \mathrm{Cl}_{2}$ (2003.8): C, 48.54; H, 4.72; N, 6.99. Found: $\mathrm{C}, 47.93$ and $48.12 ; \mathrm{H}, 4.70$ and $4.77 ; \mathrm{N}, 6.56$ and 6.70.

Heterobimetallic $\mathbf{P d}^{\mathbf{0}}-\mathbf{P t}^{\mathbf{0}}$ Complex (4). A solution of triethylamine $(0.07 \mathrm{~mL}, 0.50 \mathrm{mmol})$ in anhydrous THF $(20 \mathrm{~mL})$ was added to a degassed mixture of $8(0.044 \mathrm{~g}, 0.048 \mathrm{mmol})$ and $\mathrm{Pd}^{0}$ complex $7(0.053 \mathrm{~g}, 0.047 \mathrm{mmol})$ under argon atmosphere. The mixture was stirred at room temperature for $2.5 \mathrm{~h}$ (TLC monitoring). The solvent was removed under reduced pressure, and the residue was purified by column chromatography on silica gel ( $n$-hexane-EtOAc, polarity from 3:7 to $0: 10)$ to afford 4 as a colorless solid $(0.044 \mathrm{~g}, 47 \%)$. M.p. $187-189{ }^{\circ} \mathrm{C}$ (dec). IR (ATR): v 3377, 3285, 2925, 2856, 1598, 1325, 1152, $1092 \mathrm{~cm}^{-1} .{ }^{1} \mathrm{H} \mathrm{NMR}\left(200 \mathrm{MHz}, \mathrm{CDCl}_{3}\right.$, $\left.25{ }^{\circ} \mathrm{C}, \mathrm{TMS}\right): \delta 1.20-1.80(\mathrm{~m}, 4 \mathrm{H}(\mathrm{Pd})+4 \mathrm{H}(\mathrm{Pt})), 1.90-2.25(\mathrm{~m}, 2 \mathrm{H}(\mathrm{Pt})), 2.38(\mathrm{~s}, 12 \mathrm{H}), 2.50-3.20$ $(\mathrm{m}, 4 \mathrm{H}(\mathrm{Pd})+4 \mathrm{H}(\mathrm{Pt})), 3.10-3.45(\mathrm{~m}, 10 \mathrm{H}), 3.55-3.80(\mathrm{~m}, 2 \mathrm{H}), 3.80-4.05(\mathrm{~m}, 2 \mathrm{H}), 4.40-5.10(\mathrm{~m}$, $6 \mathrm{H}(\mathrm{Pd})+6 \mathrm{H}(\mathrm{Pt})), 5.31(\mathrm{br} \mathrm{s}, 2 \mathrm{H}), 6.32-6.58(\mathrm{~m}, 4 \mathrm{H}), 7.15-7.37(\mathrm{~m}, 10 \mathrm{H}), 7.37-7.55(\mathrm{~m}, 4 \mathrm{H})$, 7.55-7.78 (m, 10H), 7.80-8.00 (m, 4H). LSI-MS $(\mathrm{m} / \mathrm{z}): 2008[\mathrm{M}+\mathrm{H}]^{+}$. Anal. Calcd for $\mathrm{C}_{80} \mathrm{H}_{92} \mathrm{~N}_{10} \mathrm{O}_{16} \mathrm{~S}_{8} \mathrm{PdPt}$ (2007.6): C, 47.86; H, 4.62; N, 6.98. Found: $\mathrm{C}, 47.11$ and 47.43; H, 4.55 and $4.49 ; \mathrm{N}, 6.85$ and 6.77 .

\section{Acknowledgements}

We would like to thank the Spanish MICINN (projects CTQ2006-01080 and CTQ2008-05409) for their financial support. J.M. thanks the Spanish MEC for a doctoral fellowship. We thank the Research Technical Services of the UdG for spectral data.

\section{References}

1. (a) Comprehensive Supramolecular Chemistry; Atwood, J. L.; Davies, J. E. D.; MacNicol, D. D.; Vögtle, F. Eds.; Pergamon, Oxford, 1996. (b) Coordination Chemistry of Macrocyclic Compounds; Constable, E. C. Oxford University Press, 1999. (c) Macrocyclic Chemistry; Dietrich, B.; Viout, P.; Lehn, J-M, VCH, Weinheim, 1993.

2. (a) Cortés, J.; Moreno-Mañas, M.; Pleixats, R. Eur. J. Org. Chem. 2000, 239. (b) Cerezo, S.; Cortés, J.; Galvan, D.; Lago, E.; Marchi, C.; Molins, E.; Moreno-Mañas, M.; Pleixats, R.; 
Torrejón, J.; Vallribera, A. Eur. J. Org. Chem. 2001, 329. (c) Llobet, A.; Masllorens, E.; Moreno-Mañas, M.; Pla-Quintana, A.; Rodríguez, M.; Roglans, A. Tetrahedron Lett. 2002, 43, 1425.

3. (a) Cerezo, S.; Cortés, J.; Lago, E.; Molins, E.; Moreno-Mañas, M.; Parella, T.; Pleixats, R.; Torrejón, J.; Vallribera, A. Eur. J. Inorg. Chem. 2001, 1999. (b) Moreno-Mañas, M.; Pleixats, R.; Sebastián, R. M.; Vallribera, A.; Roglans, A. J. Organomet. Chem. 2004, 689, 3669. (c) Moreno-Mañas, M.; Pleixats, R.; Roglans, A.; Sebastián, R. M.; Vallribera, A. Arkivoc 2004, 4, 109.

4. Masllorens, J.; Roglans, A.; Moreno-Mañas, M.; Parella, T. Organometallics 2004, 23, 2533.

5. Sandford, G. Chem. Eur. J. 2003, 9, 1464.

6. (a) Lukin, O.; Recker, J.; Böhmer, A.; Müller, W. M.; Kubota, T.; Okamoto, Y.; Nieger, M.; Fröhlich, R.; Vögtle, F. Angew. Chem. Int. Ed. 2003, 42, 442. (b) Lukin, O.; Kubota, T.; Okamoto, Y.; Kaufmann, A.; Vögtle, F. Chem. Eur. J. 2004, 10, 2804.

7. (a) Pla-Quintana, A.; Roglans, A.; Vicente de Julián-Ortiz, J.; Moreno-Mañas, M.; Parella, T.; Benet-Buchholz, J.; Solans, X. Chem. Eur. J. 2005, 11, 2689. (b) Pla-Quintana, A.; Torrent, A.; Dachs, A.; Roglans, A.; Pleixats. R.; Moreno-Mañas, M.; Parella, T.; BenetBuchholz, J. Organometallics 2006, 25, 5612.

8. (a) Johnson Jr, C.S. Prog NMR Spec. 1999, 34, 203. (b) Cohen, Y.; Avram, L.; Frish, L. Angew. Chem. Intl. Ed. 2005, 44, 520. (c) Pregosin, P.S.; Anil Kumar P.G.; Fernández, I. Chem. Rev. 2005, 105, 2977.

9. Jerschow, A.; Muller, N. J. Magn. Reson. 1997, 125, 372. 